\title{
High mitochondrial mutation rates estimated from deep-rooting Costa Rican pedigrees
}

\author{
Lorena Madrigal ${ }^{1}$, Loredana Castrì ${ }^{2}$, Mauricio Melendez-Obando ${ }^{3}$, Ramon Villegas-Palma ${ }^{3}$, \\ Ramiro Barrantes ${ }^{4}$, Henrieta Raventos ${ }^{4}$, Reynaldo Pereira ${ }^{4}$, Donata Luiselli ${ }^{2}$, Davide \\ Pettener $^{2}$, and Guido Barbujani ${ }^{5}$ \\ ${ }^{1}$ Department of Anthropology, University of South Florida. 4202 E. Fowler Av. Tampa, FL. 3360 \\ ${ }^{2}$ Dipartimento di Biologia evoluzionistica sperimentale. Area di Antropologia. Università di \\ Bologna. Via Selmi, 3 - 40126 Bologna, Italy \\ ${ }^{3}$ Academia Costarricense de Ciencias Genealógicas. 1771-1002, Paseo de los Estudiantes, San \\ José, Costa Rica \\ ${ }^{4}$ Escuela de Biología, Universidad de Costa Rica, Ciudad Universitaria Rodrigo Facio, San Pedro \\ de Montes de Oca, 2050, Costa Rica Universidad de Costa Rica \\ ${ }^{5}$ Dipartimento di Biologia ed Evoluzione, Università di Ferrara. Via L. Borsari 4644121 Ferrara \\ Italy
}

\begin{abstract}
Estimates of mutation rates for the noncoding hypervariable Region I (HVR-I) of mitochondrial DNA (mtDNA) vary widely, depending on whether they are inferred from phylogenies (assuming that molecular evolution is clock-like) or directly from pedigrees. All pedigree-based studies so far were conducted on populations of European origin. In this paper we analyzed 19 deep-rooting pedigrees in a population of mixed origin in Costa Rica. We calculated two estimates of the HVRI mutation rate, one considering all apparent mutations, and one disregarding changes at sites known to be mutational hot spots and eliminating genealogy branches which might be suspected to include errors, or unrecognized adoptions along the female lines. At the end of this procedure, we still observed a mutation rate equal to $1.24 \times 10^{-6}$, per site per year, i.e., at least three-fold as high as estimates derived from phylogenies. Our results confirm that mutation rates observed in pedigrees are much higher than estimated assuming a neutral model of long-term HVRI evolution. We argue that, until the cause of these discrepancies will be fully understood, both lower estimates (i.e., those derived from phylogenetic comparisons) and higher, direct estimates such as those obtained in this study, should be considered when modeling evolutionary and demographic processes.
\end{abstract}

\section{Keywords}

mitochondrial DNA; population genetics; mutation rate; divergence rate

\begin{abstract}
Placing demographic events in the appropriate time frame is crucial in the study of human evolution. Dates of demographic changes, such as population expansions or splits, are often estimated from DNA variation, under the assumption that mutations accumulate at an approximately steady pace through time. This is often referred to as the molecular clock
\end{abstract}

Correspondence to: Guido Barbujani, Dept. Biology and Evolution, University of Ferrara, Via L. Borsari 46, 44121 Ferrara Italy, g.barbujani@unife.it. 
hypothesis, and considering how many studies on the origin and microevolution of the human species rely on mitochondrial DNA (mtDNA) molecular clocks (Batini et al., 2011; Bonne-Tamir et al., 2003; Brucato et al., 2010; Chaubey et al., 2008; Crubezy et al., 2010; Forster et al., 1996; Gonzalez et al., 2007; Zhu et al., 2009), one would imagine that the rate of change in mtDNA is well understood and precisely measured. However, that is not really the case. Indeed, evidence has been accumulating since the 1990's that estimates of the mtDNA mutation rate vary widely, not only according to the estimation method used, but also between populations studied using the same method -compare, e.g., Swedes and Icelanders, respectively in (Cavelier et al., 2000; Siguroardottir et al., 2000).

The two main classes of methods differ in that they infer the mutation rate either directly, counting the mutations observed in pedigrees, or indirectly, from phylogenetic comparisons. Under the latter approach, the nucleotide substitutions between different sequences are counted; corrections may be introduced for different rates of transition and transversion, and for the possibility of repeated mutations at the same nucleotide site; finally, the figures obtained are calibrated, i.e., divided by an independent estimate of the time since the common ancestor of the subjects studied (Endicott and Ho, 2008; Lundstrom et al., 1992; Nabholz et al., 2008; Ward et al., 1991). Studies of this kind, sometimes labeled either as 'model-based' or 'model-free' depending on the weight of the underlying assumptions, yield rates ranging from 0.12 to 0.38 per base pair per million years for the human first mitochondrial hypervariable region, or HVR-I (Henn et al., 2009; Ho et al., 2011). Forster et al. (1996) used a more complex model incorporating the effects of changes in population size; they obtained an estimate of 1 transition every 20,180 years which, over the 375 base pairs considered, translates into 0.13 transitions per site per million years. That figure was widely used in successive studies. By contrast, much higher estimates were obtained by directly counting the mutations in pedigrees, up to 2.50 mutations per base pair per million years (Henn et al., 2009; Heyer et al., 2001; Ho et al., 2011; Ho et al., 2007; Howell et al., 1996; Howell et al., 2003; Parsons et al., 1997; Santos et al., 2008; Santos et al., 2005; Siguroardottir et al., 2000).

The higher pedigree-derived mutation rates have several potential causes. It might be that mutational events observed in recently-recorded meiotic events are "erased" by events such as back mutations, when recorded at a macroevolutionary time frame. Other explanations for this disparity include random genetic drift, unaccounted heteroplasmy (Zaragoza et al., 2010) and a different tendency of different mtDNA sites to be damaged (Howell et al., 2003; Pereira et al., 2011; Soares et al., 2009). Indeed some sites within the mtDNA HVR-I (mutational hot spots, or "speedy sites") seem to undergo substitution four to five times as fast as the average sites (Bandelt et al., 2000; Excoffier and Yang, 1999; Wakeley, 1993). Finally, even mutations in non-coding regions may evolve in a non-neutral way, because selection affects the transmission of mtDNA (Pereira et al., 2011), these mutations are in linkage disequilibrium with mutations in coding regions, and recombination is little (Awadalla et al., 1999) or nil. This implies that the haplotype on which a new HVR-I mutation occurs, i.e., the combination of alleles in the mitochondrial genome, affects the mutation's probability to be transmitted through generations. Haplotypes sharing the same mutations in coding regions will tend to have the same apparent mutation rate in HVR-I, because they will undergo the same selective pressure; by contrast, the same HVR-I site may appear to mutate at different rates in haplotypes having different fitnesses due to mutations in the coding region. As a consequence, one should not take for granted that mutation rates estimated in different populations should necessarily coincide, because the genetic background on which the mutation occurs may contribute to determining successive changes in its frequency. 
In short, knowing exactly the mitochondrial mutation rate is at the same time complicated, and of crucial importance for accurately reconstructing population history. Because all available direct estimates refer to populations of European ancestry, an additional question is whether populations with different genetic backgrounds will show similar patterns, and comparable rates, of mutation. In this paper we took advantage of the availability of deeprooting pedigrees collected in Costa Rica, and going back to the 1500s. These pedigrees come from a mixed population and so offered us the opportunity to estimate the HVR-I mutation rate in people in which such studies have never been carried out. We used a pedigree-based approach to compute the observed mutation rate, as well as a number of related statistics. We obtained very high initial estimates; by stepwise eliminating pedigrees which, one way or another, may not be considered reliable, and by disregarding the effects of DNA sites that may mutate at a higher-than-average rate, we showed that even under the most conservative assumptions our empirical estimate of the HVR-I mutation rate remains high.

\section{MATERIALS AND METHODS}

The data consist of maternal genealogies started from 152 living subjects, all of whom lived in Atenas, Costa Rica. The genealogies were reconstructed with records obtained from the Church Chancery and the National Document Register, and each included at least seven generations, sometimes extending all the way back to the 1500s. Only adults able to give informed consent were recruited. The project was approved by the committee on bioethics of the University of South Florida and the Universidad de Costa Rica. For this paper, we considered 19 pedigrees for which we could determine if mutational events had taken place because they included more than one living subject from whom we extracted mtDNA. Fieldwork and data collection are described elsewhere (Madrigal and Melendez-Obando, 2008). MtDNA was extracted from 152 blood samples with standard procedures. The HVRI of the mtDNA control region was amplified by PCR between nps 16024-16383 using primers H16401 and L15997. Both strands of the HVR-I were sequenced. In addition, seven binary PCR-restriction fragment length polymorphisms were typed, known to be specific to maternal lineages within America, Europe, and Africa, in order to help define the haplogroups, namely 1663HaeIII, 13592HpaI, 110397AluI, 110871MnlI, 211251 Tsp509I, 113262 AluI, 214766 MseI, and the COII/tRNAlys 9-bp deletion (Castri et al., 2009).

An initial mutation frequency was calculated by counting the number of HVR-I mutations and dividing this number by the total number of meiotic events recorded in all the pedigrees. The mutation rate per site per generation was then computed by dividing the mutation frequency by 360 , the number of base pairs sequenced. The mutation rate per site per year was computed by dividing the former by the generation time. Although several authors considered a standard generation time of 20 years (Cavelier et al., 2000; Howell et al., 2003; Parsons et al., 1997; Siguroardottir et al., 2000) for this study we had full information about the age at reproduction of the women in our sample. In the 289 meioses considered it was 28.3 years (ranging from 15 through 50 years of age), and hence we decided to use that figure. Lastly, the divergence rate is twice the mutation rate.

For computing the age at motherhood, we considered all pedigrees, namely, those which did not have more than one descendant from a single common ancestor and those analyzed in this paper. Each datum consisted of the age at motherhood for each woman in each of our pedigrees. In a few cases, the exact age was missing, and in this case, this data point was entered as missing. If a woman was the mother of more than one branch in a pedigree (as shown in the figures), her age at all of the pregnancies was considered, and a mean age at motherhood was computed for her. The mean age at motherhood used in this paper is the mean considered using all data points obtained as described here. 
Counting mutations was not always straightforward; sometimes the descendants of a common ancestor differed by more than one mutation, suggesting that an adoption might have taken place. In two pedigrees the hypothesis of adoption appeared clearly the most parsimonious, but in one case it was difficult to judge whether there had been repeated mutations in the same pedigree (number 3), or several adoptions, or errors in genealogical reporting. In addition, there is no consensus on whether nucleotide changes at sites known to mutate at a particularly high rate (the so-called "mutational hotspots" or "speedy" sites (Bandelt et al., 2000; Excoffier and Yang, 1999; Wakeley, 1993) should or should not be considered in the calculation of the mutation rate. As a consequence, we chose to compute both a maximum and a minimum estimate of mutation rates and related statistics, respectively with and without the ambiguous pedigree number 3 , and, in the latter case, also disregarding mutations occurring at one hotspot.

Point estimates are, of course, only mildly informative. Therefore, we resorted to a Bayesian procedure to estimate an exact confidence interval about them, assuming no prior knowledge, a binomial distribution of the parameter and a beta distribution of its posterior probabilities (Jaynes, 1976).

\section{RESULTS}

A total of 19 pedigrees met the requirement that more than one living subject was typed for mtDNA (Table 1). Table 1 also shows the age at birth of the most recent common ancestor (MRCA). Sequence variations in each individual were scored relative to the revised Cambridge Reference Sequence (rCRS) (Andrews et al., 1999). Typically Amerindian sequences of haplogroups A, B, C and D represented $89 \%$ of the total; typically European sequences of the haplogroups $\mathrm{H}$ and $\mathrm{J}$ account for a further $10 \%$ of the total; one individual sequence belongs to haplogroup L4b2, generally observed in subjects of African ancestry. Figure 1 shows one of the pedigrees (\# 4) in which no mutations were detected, while Figure 2 shows a pedigree (\#3) in which there were either repeated mutations, several adoptions or errors in genealogical reporting. All other pedigrees are shown in Supplementary Figures S1-S17. The pedigrees with the number of mitosis and mutations involved are listed in Table 1.

In pedigree number 2 , the two living subjects apparently differ by 9 mutations. Clearly, the simplest explanation for that finding is that one of their female ancestors was actually adopted, and hence we discarded this pedigree. Similarly, in pedigree number 17, the three living subjects had the same HVRI sequence, but one of them differed from the others by mutations at two sites in the coding region (573 $\mathrm{nC}$ and 10806Hpal). Therefore, we excluded from the analysis the relevant section of this pedigree, which, accordingly, contributes to further calculations no substitutions and five instead of 10 meiotic events.

After this, we observed a total of 7 mutational events (plus one mutation in the coding region) over a total of 299 meioses, occurring at the following sites: 16,131; 16,182 (twice); 16,$311 ; 16,335 ; 16,344 ; 16,362$. In this and all following cases, the empirical HVR-I mutation rate was estimated by dividing the number of mutations by the number of meiotic divisions, namely $\frac{7}{273}=0.0256$ per generation. Over the 360 sites of HVRI, this means 71.1 $\times 10^{-6}$ substitutions per site per generation, and assuming a (female) average generation interval of 28.3 years, $2.51 \times 10^{-6}$ substitutions per site per year. Our divergence rate is then $=5.02 \times 10^{-6}$ substitutions per site per year. These values are much higher than those estimated by Howell et al.'s (2003), and 13 to 42 times as high as most phylogenetic estimates for HVR-I, all in the range 0.12 to $0.38 \times 10^{-6}$ substitutions per site per year 
(Forster et al., 1996; Henn et al., 2009; Ho et al., 2011). These are what we refer to as our maximum estimates.

Three apparent mutational events were observed in the same pedigree, pedigree number 3 (shown in figure 2), where 4 different HVR-I motifs were observed, each differing from its nearest neighbor by one substitution. To be sure that no error had occurred in sequencing, all these sequences were independently replicated and confirmed. Therefore, one cannot easily rule out the possibility that what we observed is really the consequence of repeated mutations occurring in the same pedigree. On the other hand, it is also conceivable that this variation might result from adoption of several girls, or from errors in genealogical reporting, or from a combination of all these factors. We had no way to directly test whether that was actually the case, and hence we redid the estimation procedure, eliminating that pedigree from the analysis, thus losing 3 mutations and 43 meioses. We also considered that nucleotide position 16,182 (pedigree number 11) occurs in a stretch rich in C-nucleotides, known to sometimes cause apparent length polymorphism and subsequent typing errors (Bandelt and Kivisild, 2006; Soares et al., 2009). Thus, we excluded this pedigree as well, thus losing one mutation and 10 informative meioses. Finally, of the sites where mutations were observed, Bandelt et al. (2000) report as mutational hot spots (or "speedy" sites) $16,311,16,335$, and 16,362. After elimination of pedigrees number 3 and 17, only one such mutation remained (site 16,335) and is likely to inflate the apparent mutation rates. For the estimation of a minimum value of the mutation rate, it seemed logical to treat this mutation as not informative, without disregarding the information represented by the 9 meioses in pedigree 10 . Therefore, our minimum estimate of the observed mutation rate is $2 / 220=$ 0.0091 , or $25.3 \times 10^{-6}$ substitutions per site per generation, and $0.89 \times 10^{-6}$ substitutions per year. Accordingly, the divergence rate became $=1.78 \times 10^{-6}$ per year.

Table 2 shows the confidence intervals about our two estimates. Based on the pedigrees of this study, and under the most conservative assumptions (i.e., considering the minimum estimate obtained) we can conclude that the HVR-I mutation rate in the Costa Rican population of Atenas has $95 \%$ probability to fall between 0.27 and $3.17 \times 10^{-6}$ substitutions per site per year. In other words, the lower limit of our estimate is approximately twice as high as the most commonly accepted phylogenetic estimate, namely $0.13 \times 10^{-6}$.

\section{DISCUSSION}

In this paper we showed that high empirical HVR-I mutation rates are inferred from the analysis of pedigrees of a mixed Central American population. We also found that neither assumptions on the interval between generations nor presence in the pedigree of adopted individuals are possible explanations for the high values observed. Indeed, the generation length for what we consider the most plausible estimate was not assumed, but calculated from the data, and is among the most conservative values used so far (Table 3 ). Similarly, we eliminated from the sample all instances of possible adoptions, and still the estimates (and their lower confidence limits) remained much higher than those resulting from phylogenetic analyses, and of the same order of magnitude as those inferred from studies of European pedigrees.

In the last decade, the controversy surrounding the rate of mtDNA evolutionary change has increased to include discussions of the rate of change in coding regions (Elson et al., 2004; Kivisild et al., 2006), the role of purifying selection (Soares et al., 2009), the relation between mtDNA phylogeny and pathogenicity of mitochondrial variants (Elson et al., 2004; Mishmar and Zhidkov, 2010), the possible role of climate as a selective force on mtDNA diversity and the relation between time scale and molecular rate estimates (Emerson, 2007; Endicott et al., 2009; Ho et al., 2007; Macaulay et al., 1997). Bandelt (2008) stressed that 
every individual is likely heteroplasmic, i.e., harbors several related variants; this withinindividual variation creates uncertainty about the estimates obtained comparing mother and child As a matter of fact, the process through which a mutation initially occurring in a single mtDNA molecule reaches fixation in an individual's cells is far from being understood. However, this way heteroplasmy introduces a large bias in the estimates only if one or a few meioses are considered; hence, it can hardly account for the repeatedly observed difference between the estimates coming from phylogenetic and pedigree studies. With one exception (Cavelier et al., 2000) the latter are much higher; our maximum estimate, $2.51 \times 10^{-6}$ is very close to the highest value ever reported (Parsons et al., 1997), whereas our minimum estimate is a still high 0.92 per site per million years.

Whether or not, and to what extent, it is legitimate to extrapolate rates of change estimated over a few generations across different evolutionary timescales is open to discussion. However, our results clearly support previous proposals suggesting that the apparent rate of change at the microevolutionary level is faster than that seen at a macroevolutionary level. Two open questions, then, are why different approaches lead to such different results, and which values represent a plausible approximation for dating events, or for simulation studies, when mutation rates cannot be estimated from the data. Our pedigrees do not allow us to speculate on the reasons for the disparity of estimates based on the two methods, but, as for the second question, it seems reasonable that the time-depth of the study might dictate the choice of the appropriate mutation rate, or at least that a range of values should be considered.

That does not seem to be currently the case. Table 4 shows the values chosen by several authors in studies at different time-scales, from 3,000 to several hundred thousand years. In most such studies, mitochondrial gene genealogies, either reconstructed from data on current variation or generated by computer simulation, were interpreted under the assumption that mutation rates are low or very low. Only in a subset of studies was a range of possible values explored (Destro-Bisol et al., 2004; Guimaraes et al., 2009; Zlojutro et al., 2009). However, in one such case (Destro-Bisol et al., 2004) the maximum mutation rate considered was well below the values estimated in almost all pedigree-based studies.

Until the causes of the discrepancy between mutation rates estimates will be fully understood, our study and similar pedigree-based analyses suggest at least that HVR-I mutation rates around 0.10 per site per million years should be taken with a grain of salt. By making rigid assumptions based on that figure, one radically dismisses the empirical evidence available in favor of a faster-ticking evolutionary clock. This way, the risk is to erroneously locate in a remote past relatively recent events, thus distorting our perception of our evolutionary trajectory. At present, a prudent choice seems then to consider in the analyses both a slow- and a fast-ticking mitochondrial clock, evaluating the evolutionary consequences of the models under a broad range of assumptions.

\section{Supplementary Material}

Refer to Web version on PubMed Central for supplementary material.

\section{Acknowledgments}

This project was supported by a grant from the National Institutes of Aging (1-R03-AG022616-01) to LM and by Italian Ministry of Universities and Research (MIUR) Grants to DP, DL and GB.

We dedicate this paper to the memory of Loredana Castrì. We thank the people of Atenas for their support of this project. We acknowledge the support of Ms. Caitlin Buckhout in the production of the pedigree figures. 


\section{Literature cited}

Andrews RM, Kubacka I, Chinnery PF, Lightowlers RN, Turnbull DM, Howell N. Reanalysis and revision of the Cambridge reference sequence for human mitochondrial DNA. Nat Genet. 1999; 23:147-147. [PubMed: 10508508]

Awadalla P, Eyre-Walker A, Smith JM. Linkage disequilibrium and recombination in hominid mitochondrial DNA. Science. 1999; 286:2524-2525. [PubMed: 10617471]

Bandelt HJ, Kivisild T. Quality assessment of DNA sequence data: autopsy of a mis-sequenced mtDNA population sample. Ann Hum Genet. 2006; 70:314-326. [PubMed: 16674554]

Bandelt HJ, Macaulay V, Richards M. Median networks: speedy construction and greedy reduction, one simulation, and two case studies from human mtDNA. Mol Phylogenet Evol. 2000; 16:8-28. [PubMed: 10877936]

Batini C, Lopes J, Behar DM, Calafell F, Jorde LB, van der Veen L, Quintana-Murci L, Spedini G, Destro-Bisol G, Comas D. Insights into the demographic history of African pygmies from complete mitochondrial genomes. Mol Biol Evol. 2011; 28:1099-1110. [PubMed: 21041797]

Bonne-Tamir B, Korostishevsky M, Redd AJ, Pel-Or Y, Kaplan ME, Hammer MF. Maternal and paternal lineages of the Samaritan isolate: mutation rates and time to most recent common male ancestor. Ann Hum Genet. 2003; 67:153-164. [PubMed: 12675690]

Brucato N, Cassar O, Tonasso L, Tortevoye P, Migot-Nabias F, Plancoulaine S, Guitard E, Larrouy G, Gessain A, Dugoujon J-M. The imprint of the slave trade in an African American population: mitochondrial DNA, Y chromosome and HTLV-1 analysis in the Noir Marron of French Guiana. BMC Evol Biol. 2010:10. [PubMed: 20067644]

Castri L, Melendez-Obando M, Villegas-Palma R, Barrantes R, Raventos H, Pereira R, Luiselli D, Pettener D, Madrigal L. Mitochondrial polymorphisms are associated both with increased and decreased longevity. Hum Hered. 2009; 67:147-153. [PubMed: 19077432]

Cavelier L, Jazin E, Jalonen P, Gyllensten U. MtDNA substitution rate and segregation of heteroplasmy in coding and noncoding regions. Hum Genet. 2000; 107:45-50. [PubMed: 10982034]

Chaubey G, Karmin M, Metspalu E, Metspalu M, Selvi-Rani D, Singh VK, Parik J, Solnik A, Naidu P, Kumar A, et al. Phylogeography of mtDNA haplogroup R7 in the Indian peninsula. BMC Evol Biol. 2008:8. [PubMed: 18197981]

Crubezy E, Amory S, Keyser C, Bouakaze C, Bodner M, Gibert M, Rock A, Parson W, Alexeev A, Ludes B. Human evolution in Siberia: from frozen bodies to ancient DNA. BMC Evol Biol. 2010; 10:16. [PubMed: 20089168]

Destro-Bisol G, Coia V, Boschi I, Verginelli F, Caglia A, Pascali V, Spedini G, Calafell F. The analysis of variation of mtDNA hypervariable region 1 suggests that Eastern and Western pygmies diverged before the Bantu expansion. Am Nat. 2004; 163:212-226. [PubMed: 14970923]

Elson JL, Turnbull DM, Howell N. Comparative genomics and the evolution of human mitochondrial DNA: assessing the effects of selection. Am J Hum Genet. 2004; 74:229-238. [PubMed: 14712420]

Emerson BC. Alarm bells for the molecular clock? No support for Ho et al.'s model of time-dependent molecular rate estimates. Syst Biol. 2007; 56:337-345. [PubMed: 17464888]

Endicott P, Ho SYW. A Bayesian evaluation of human mitochondrial substitution rates. Am J Hum Genet. 2008; 82:895-902. [PubMed: 18371929]

Endicott P, Ho SYW, Metspalu M, Stringer C. Evaluating the mitochondrial timescale of human evolution. Trends Ecol Evol. 2009; 24:515-521. [PubMed: 19682765]

Excoffier L, Yang ZH. Substitution rate variation among sites in mitochondrial hypervariable region I of humans and chimpanzees. Mol Biol Evol. 1999; 16:1357-1368. [PubMed: 10563016]

Forster P, Harding R, Torroni A, Bandelt HJ. Origin and evolution of Native American mtDNA variation: a reappraisal. Am J Hum Genet. 1996; 59:935-945. [PubMed: 8808611]

Gonzalez AM, Larruga JM, Abu-Amero KK, Shi Y, Pestano J, Cabrera VM. Mitochondrial lineage M1 traces an early human backflow to Africa. BMC Genomics. 2007:8. [PubMed: 17210083] 
Guimaraes S, Ghirotto S, Benazzo A, Milani L, Lari M, Pilli E, Pecchioli E, Mallegni F, Lippi B, Bertoldi F, et al. Genealogical discontinuities among Etruscan, medieval, and contemporary Tuscans. Mol Biol Evol. 2009; 26:2157-2166. [PubMed: 19570745]

Henn BM, Gignoux CR, Feldman MW, Mountain JL. Characterizing the time dependency of human mitochondrial DNA mutation rate estimates. Mol Biol Evol. 2009; 26:217-230. [PubMed: 18984905]

Heyer E, Zietkiewicz E, Rochowski A, Yotova V, Puymirat J, Labuda D. Phylogenetic and familial estimates of mitochondrial substitution rates: study of control region mutations in deep-rooting pedigrees. Am J Hum Genet. 2001; 69:1113-1126. [PubMed: 11582570]

Ho SYW, Lanfear R, Bromham L, Phillips MJ, Soubrier J, Rodrigo AG, Cooper A. Time-dependent rates of molecular evolution. Mol Ecol. 2011; 20:3087-3101. [PubMed: 21740474]

Ho SYW, Shapiro B, Phillips MJ, Cooper A, Drummond AJ. Evidence for time dependency of molecular rate estimates. Syst Biol. 2007; 56:515-522. [PubMed: 17562475]

Howell N, Kubacka I, Mackey DA. How rapidly does the human mitochondrial genome evolve? Am J Hum Genet. 1996; 59:501-509. [PubMed: 8751850]

Howell N, Smejkal CB, Mackey DA, Chinnery PF, Turnbull DM, Herrnstadt C. The pedigree rate of sequence divergence in the human mitochondrial genome: There is a difference between phylogenetic and pedigree rates. Am J Hum Genet. 2003; 72:659-670. [PubMed: 12571803]

Kivisild T, Shen PD, Wall DP, Do B, Sung R, Davis K, Passarino G, Underhill PA, Scharfe C, Torroni A, et al. The role of selection in the evolution of human mitochondrial genomes. Genetics. 2006; 172:373-387. [PubMed: 16172508]

Lundstrom R, Tavare S, Ward RH. Estimating substitution rates from molecular-data using the coalescent. Proc Natl Acad Sci USA. 1992; 89:5961-5965. [PubMed: 1631081]

Macaulay VA, Richards MB, Forster P, Bendall KE, Watson E, Sykes B, Bandelt HJ. mtDNA mutation rates: no need to panic. Am J Hum Genet. 1997; 61:983-986. [PubMed: 9382113]

Madrigal L, Melendez-Obando M. Grandmothers' longevity negatively affects daughters' fertility. Am J Phys Anthropol. 2008; 136:223-229. [PubMed: 18322917]

Mishmar D, Zhidkov I. Evolution and disease converge in the mitochondrion. BBA-Bioenergetics. 2010; 1797:105-105.

Nabholz B, Glemin S, Galtier N. Strong variations of mitochondrial mutation rate across mammals: the longevity hypothesis. Mol Biol Evol. 2008; 25:120-130. [PubMed: 17998254]

Parsons TJ, Muniec DS, Sullivan K, Woodyatt N, Alliston Greiner R, Wilson MR, Berry DL, Holland KA, Weedn VW, Gill P, et al. A high observed substitution rate in the human mitochondrial DNA control region. Nat Genet. 1997; 15:363-368. [PubMed: 9090380]

Pereira L, Soares P, Radivojac P, Li B, Samuels DC. Comparing phylogeny and the predicted pathogenicity of protein variations reveals equal purifying selection across the global human mtDNA diversity. Am J Hum Genet. 2011; 88:433-439. [PubMed: 21457906]

Santos C, Montiel R, Arruda A, Alvarez L, Aluja MP, Lima M. Mutation patterns of mtDNA: empirical inferences for the coding region. BMC Evol Biol. 2008:8. [PubMed: 18197981]

Santos C, Montiel R, Sierra B, Bettencourt C, Fernandez E, Alvarez L, Lima M, Abade A, Aluja MP. Understanding differences between phylogenetic and pedigree-derived mtDNA mutation rate: a model using families from the Azores Islands (Portugal). Mol Biol Evol. 2005; 22:1490-1505. [PubMed: 15814829]

Siguroardottir S, Helgason A, Gulcher JR, Stefansson K, Donnelly P. The mutation rate in the human mtDNA control region. Am J Hum Genet. 2000; 66:1599-1609. [PubMed: 10756141]

Soares P, Ermini L, Thomson N, Mormina M, Rito T, Roehl A, Salas A, Oppenheimer S, Macaulay V, Richards MB. Correcting for purifying selection: an improved human mitochondrial molecular clock. Am J Hum Genet. 2009; 84:740-759. [PubMed: 19500773]

Wakeley J. Substitution rate variation among sites in hypervariable region 1 of human mitochondrial DNA. J Mol Evol. 1993; 37:613-623. [PubMed: 8114114]

Ward RH, Frazier BL, Dewjager K, Paabo S. Extensive mitochondrial diversity within a single Amerindian tribe. Proc Natl Acad Sci USA. 1991; 88:8720-8724. [PubMed: 1681540]

Zaragoza MV, Fass J, Diegoli M, Lin D, Arbustini E. Mitochondrial DNA variant discovery and evaluation in human cardiomyopathies through next-generation sequencing. PLoS One. 2010; 5(8) 
Zhu Y, Li Q, Chen Z, Kun Y, Liu L, Liu X, Yuan H, Zhai S, Han D, Dai P. Mitochondrial haplotype and phenotype of 13 Chinese families may suggest multi-original evolution of mitochondrial C1494T mutation. Mitochondrion. 2009; 9:418-428. [PubMed: 19682603]

Zlojutro M, Tarskaia LA, Sorensen M, Snodgrass JJ, Leonard WR, Crawford MH. Coalescent simulations of Yakut mtDNA variation suggest small founding population. Am J Phys Anthropol. 2009; 139:474-482. [PubMed: 19235790] 


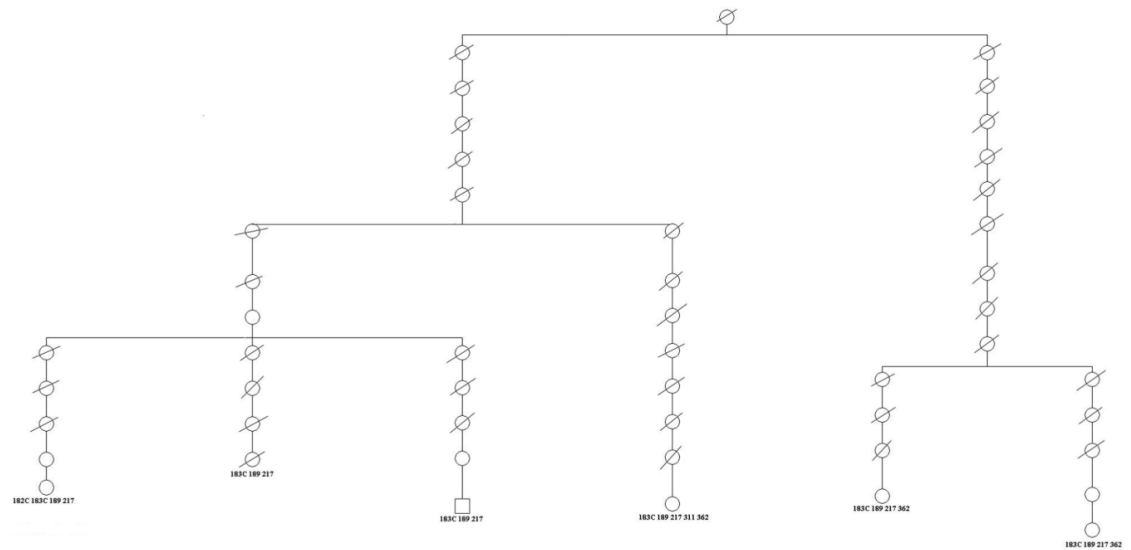

Figure 1.

Pedigree \#4. This pedigree shows that no mutations occurred in any of the descendants of the last common ancestor. 


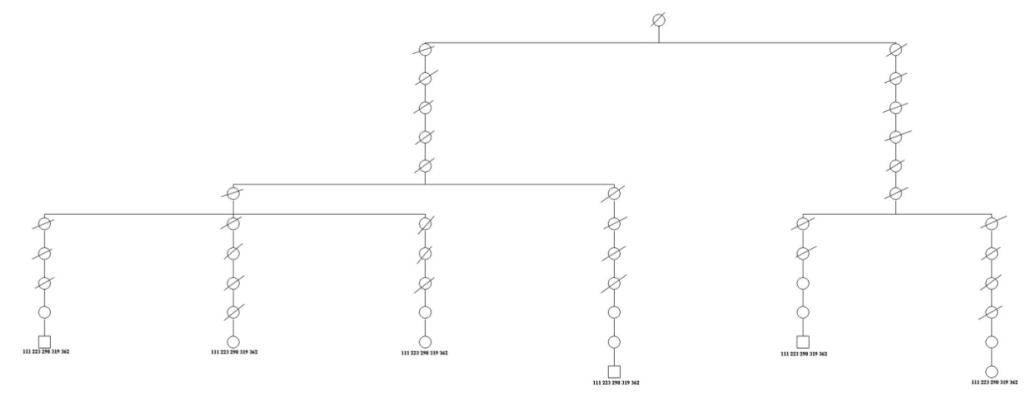

Figure 2.

Pedigree \#3. There are three mutations, adoptions or genealogical errors in this pedigree. 

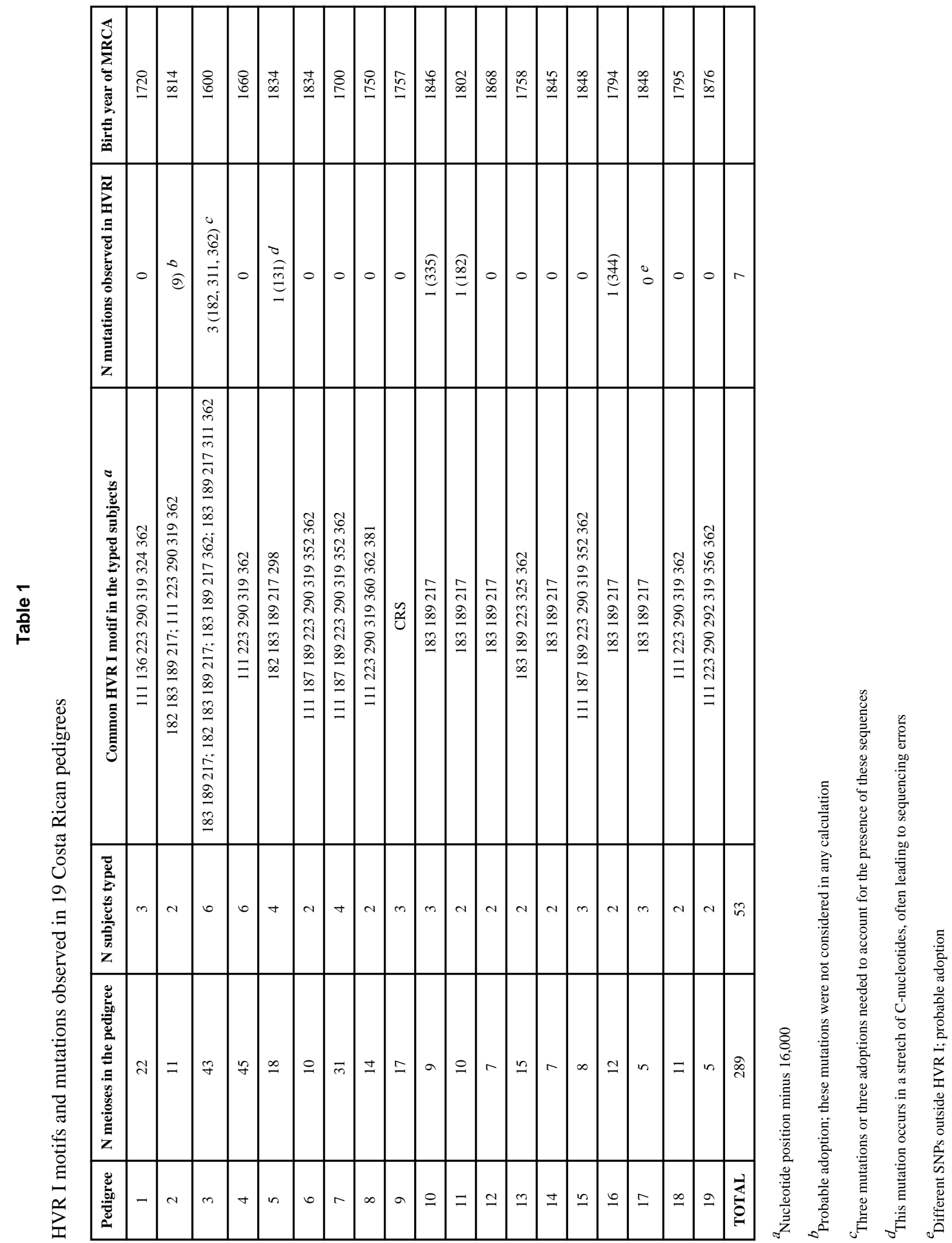


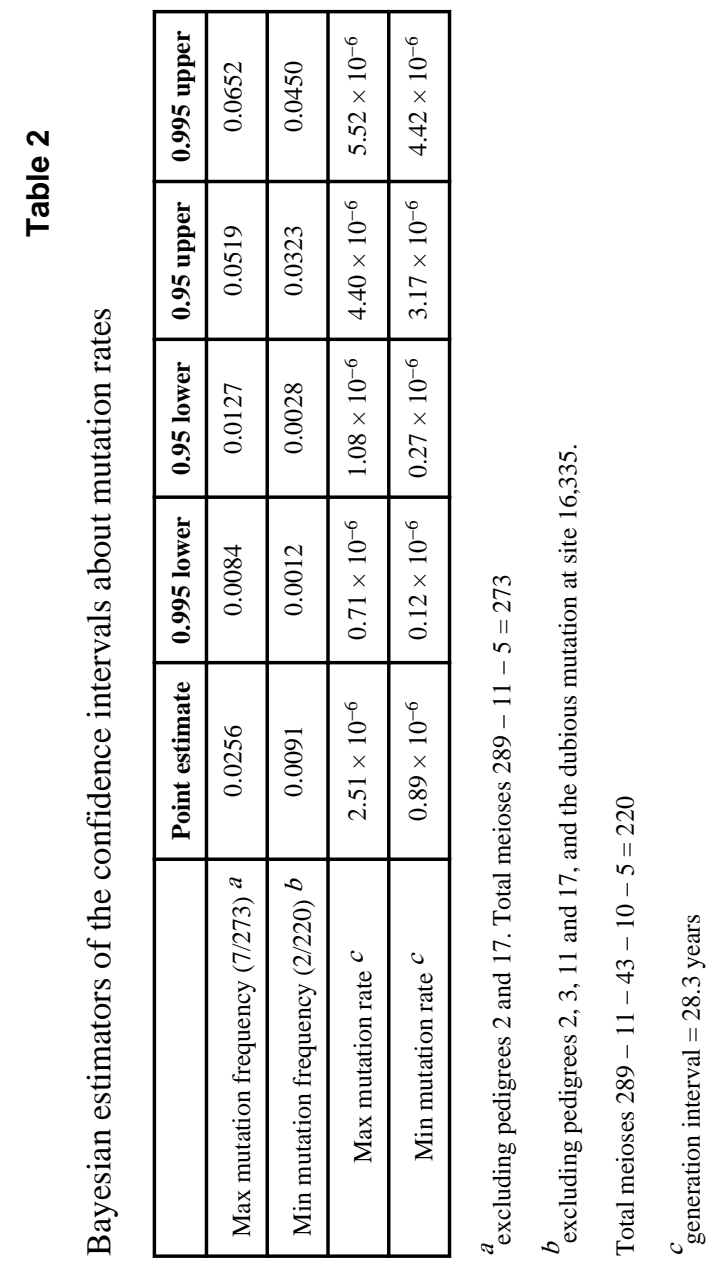


Table 3

Comparison with other pedigree studies

\begin{tabular}{|l|c|c|c|c|}
\hline Reference & Mutations/generations & Generation interval (years) & $\begin{array}{c}\text { Mut. Rate per site } \\
\text { per million years }\end{array}$ & Population studied \\
\hline Parsons et al., 1997 & $10 / 327$ & 20 & 2.50 & European-origin samples \\
\hline Sigurdarđóttir et al. 2000 & $5 / 705$ & 20 & 0.32 & Icelanders \\
\hline Cavelier et al. 2000 & $0 / 292$ & 20 & 0.00 & Swedish \\
\hline Heyer et al. 2001 & $4 / 508$ & 30 & 0.35 & French-Quebecois \\
\hline Howell et al. 2003 & $3 / 263$ & 20 & 0.51 & Unspecified European \\
\hline Santos et al. 2005 & & 25 & 0.24 & Azores Islands \\
\hline This study (minimum estimate) & $2 / 212$ & 28.3 & 0.92 & Costa Rican \\
\hline
\end{tabular}

${ }^{a}$ There were several estimates in this paper. We report the one inferred from the pooled dataset, referred to as 'University of Texas Medical Branch pooled'

$b$

Both males and females were considered in the analysis, and so initial estimates of mutation rate were corrected taking into account the impossibility for males to transmit the mutations to the next generation 
Table 4

Assumed generation times and assumed HVRI mutation rates in studies of human evolution

\begin{tabular}{|l|c|c|l|}
\hline Reference & Generation time & $\begin{array}{c}\text { HVRI Mutation rate } \\
\text { per site per million } \\
\text { years }\end{array}$ & Subject of the study and time scale \\
\hline (Ray et al. 2003) & 25 & 0.13 & Pleistocene spatial expansions $>110,000$ years BP \\
\hline (Destro-Bisol et al. 2004) & 25 & $0.042-0.18$ & Divergence between Pygmies and Bantu, $>18,000$ years BP \\
\hline (Tishkoff et al. 2007) & 25 & 0.10 & Demographic history of African click-speakers, $>35,000$ years BP \\
\hline (Chaix et al. 2008) & 29 & 0.35 & East-West population expansions in Eurasia, $>25,000$ years BP \\
\hline (Guimaraes et al. 2009) & 25 & $0.05-0.50$ & $\begin{array}{l}\text { Genealogical relationships between Etruscans and Tuscans, }>3,000 \\
\text { years BP }\end{array}$ \\
\hline (Zlojutro et al. 2009) & 25 & $0.05-0.50$ & Upper Paleolithic origin of the Yakuts, $>30,000$ years BP \\
\hline (de Filippo et al. 2010) & 25 & 0.10 & African population divergence, $>62,500$ years BP \\
\hline (Ghirotto et al. 2011) & 25 & $0.05-0.50$ & $\begin{array}{l}\text { Genealogical relationships between Neandertals and modern } \\
\text { Europeans, }>200,000 \text { years BP }\end{array}$ \\
\hline
\end{tabular}

